\title{
Effects of elastic band resistance exercises with breathing techniques on pulmonary function in female seniors
}

\author{
Kyoung Kim, Ji Won Han*, Young Mi Kim \\ Department of Physical Therapy, College of Rehabilitation Science, Daegu University, Daegu, Korea
}

The purpose of this study was to investigate the effects of elastic-band resistance exercises combined with breathing techniques on pulmonary function in female seniors. Forty-five female seniors 65 years or older were recruited from a welfare center and assigned to an experimental $(n=23)$ or control $(n=22)$ group. The experimental group used an elastic band with a resistance exercises while concurrently using specific breathing techniques. The control group conducted the same resistance tasks without the respiration exercises. Respiratory function data were collected before and after the 6-week intervention. The ex- perimental group showed a significant increase in forced vital capacity $(F V C)$, forced expiratory volume $1 \mathrm{sec}\left(\mathrm{FEV}_{1}\right)$, and in $\mathrm{FEV}_{1}$ as a percentage of FVC. In addition, there were significant differences in the FVC and $\mathrm{FEV}_{1}$ levels between groups. The results show that resistance accompanied by breathing techniques positively affects senior respiratory function when an elastic band is used for exercise.

Keywords: Elastic band resistance exercises, Breathing exercises, Pulmonary function

\section{INTRODUCTION}

As the life of old age has lengthened, much attention has been paid to various solutions to the physical deterioration of the human body, and the need for regular exercise by the elderly has been recognized (Dishman et al., 2006). The process also performs mechanical functions relating to posture stabilization and balance, and affects stress, anxiety, and pain (Obayashi et al., 2012). However, as aging progresses, the respiratory system also ages, resulting in one more easily becoming out of breath from decreases in breathing capacity through degradation of elasticity in the alveoli and reduced pulmonary circulation. In addition, as breathing capacity increases, the elderly become more easily fatigued because of shrinking and weakening respiration muscles. Similarly, degradation of the cough reflex and cilia movement result in particulate matter not being filtered and secretions accumulating in the bronchus, which leads to greater susceptibility to pulmonary infections. Thus, the health status of the respiratory system plays a decisive role in the physical and social life of the elderly (Janssens et al., 1999).

Previous investigations of the effects of breathing exercises have revealed improvements in respiratory muscles and respiratory function that activated trunk control and significantly affected everyday mobility (Moodie et al., 2011; Perri and Halford, 2004; Sutbeyaz et al., 2010). Hodges and Gandevia (2000) determined that raising intra-abdominal pressure during expiration through transverse abdominis exercises had a stable impact on pulmonary function, as well as on posture control and stabilization. Hodges and Richardson (1999) also reported that when movement began in the distal segments of the upper and lower extremities, the diaphragm increased intra-abdominal pressure, thereby establishing greater trunk stability. Other previous studies have also concluded that there is a close correlation between breathing activity and postural control (Khedr et al., 2000).

A number of studies have also been conducted to identify methods of improving respiratory function through typical exer-
${ }^{*}$ Corresponding author: Ji Won Han (D) https://orcid.org/0000-0001-9739-9107 Department of Physical Therapy, College of Rehabilitation Science, Daegu University, 201 Daegudae-ro, Jillyang-eup, Gyeongsan 38453, Korea E-mail: damgeom@naver.com

Received: December 24, 2018 / Accepted: January 22, 2019
This is an Open Access article distributed under the terms of the Creative Commons Attribution Non-Commercial License (http://creativecommons.org/licenses/by-nc/4.0/) which permits unrestricted non-commercial use, distribution, and reproduction in any medium, provided the original work is properly cited. 
cises such as diaphragm breathing (Bradley and Esformes, 2014), feedback breathing (Koppers et al., 2006) and pursed-lip breathing (Sutbeyaz et al., 2010) Exercise using dumbbells or weight training tools has generated unexpected results because of difficulties in accurate motion measurement and the risk of injury. Accordingly, previous studies have emphasized the need to investigate the effects and the safety of heavy equipment in resistance exercises and claimed the need for alternative exercise tools (Andersen et al., 2010; Jakobsen et al., 2012). In contrast, elastic bands are considered suitable equipment for the elderly since it they are relatively safe and simple to use while providing similar physical strength effects to resistance exercises using existing weight training tools. Moreover, elastic bands facilitate muscle use across the entire body and are portable and economical (Colado and Triplett, 2008; Hostler et al., 2001).

Although previous studies have reported improvements in physical ability using elastic bands, none have evaluated the effects of an elastic band exercise program with breathing techniques on pulmonary function in female seniors. Therefore, this study was conducted to determine the effects of elastic band exercise with breathing techniques on elderly health as evidenced by pulmonary function. It also aims to provide a clinical basis for the prevention of pulmonary function deterioration and for improvements in pulmonary function by developing a self-directed exercise program that female seniors can follow by themselves.

\section{MATERIALS AND METHODS}

\section{Subjects}

This study enrolled attendees of the Seniors' Welfare Center who voluntarily agreed to participate and gave their informed consent. The selection criteria were that participants must be women aged over 65 years with no pathological respiratory problems such as coughing, bleeding, or difficulty in breathing for more than 2 weeks. Subjects must also have had no orthopedic restrictions on walking as of the date of the experiment. A total of

Table 1. General characteristics of two groups

\begin{tabular}{lcccc}
\hline Characteristic & EBE+MEP group $(\mathrm{n}=23)$ & EBE group $(\mathrm{n}=22)$ & $t$ & $P$-value \\
\hline Age $(\mathrm{yr})$ & $70.78 \pm 4.12$ & $72.23 \pm 6.37$ & -0.82 & 0.41 \\
Weight $(\mathrm{kg})$ & $57.86 \pm 6.05$ & $58.57 \pm 7.94$ & -0.32 & 0.75 \\
Height $(\mathrm{cm})$ & $154.37 \pm 4.04$ & $153.23 \pm 3.96$ & 0.88 & 0.38 \\
Muscle mass $(\mathrm{kg})$ & $34.99 \pm 3.13$ & $34.22 \pm 3.09$ & 0.76 & 0.45 \\
\hline
\end{tabular}

Values are presented as mean \pm standard deviation.

EBE+MEP group, elastic band exercise+maximal expiratory technique group; EBE group, elastic band exercise group.
45 participants were randomly divided into two groups: the elastic band exercise group with breathing technique $(\mathrm{n}=23)$ and the elastic band exercise only group $(n=22)$. A homogeneity test of the general characteristics of the subjects conducted before the experiment revealed no significant differences in average age, weight, height, or muscle mass between the two groups $(P>0.05)$ (Table 1).

The respiratory measurements were conducted by the same expert who was familiar with all the procedures in the experiment to maintain consistency. The exercise program was conducted three times a week for six weeks. The 45 participants who agreed to participate provided written informed consent. In addition, the study was approved by the Daegu University Institutional Review Board for Human Studies Committee and conducted in accordance with the Declaration of Helsinki (IRB No. 10406212017.09.-HR-003-02).

\section{Procedure}

Dynamic exercises using an elastic band were conducted using a band offering $40 \%$ resistance on one-repetition maximum (1RM) values (Thera-Band). Participants assumed a hook-lying position, lying flat on a yoga mat and bending hips and knees with eyes directed to the ceiling. The elastic band exercise was designed by improving the method used by Nyberg et al. (2015) according to the purpose of the current experiment (Table 2). A breathing technique was conducted together with the resistance exercise to provide maximum expiration. In this method, participants breathed in through their nose for $3 \mathrm{sec}$, then breathed deeply out as much as possible while contracting the abdomen muscles using the controlled breathing technique of saying "Shhhh" during exhalation (Ishida et al., 2012). During preparation for the elastic band exercise, participants were made ready by adopting the above breathing technique so that it could be used as soon as the exercise began. The total exercise time was set to 40 min.

For the elastic band only group, the same band was used to conduct the same exercise, but breathing was conducted freely. The pulmonary function test employed a Spirometer (Pony FX,

Table 2. Dynamic exercises

\begin{tabular}{lc}
\hline Type & Dynamic exercises method \\
\hline A & Elbow flexion \\
B & Shoulder flexion \\
C & Knee extension \\
D & Hip extension \\
\hline
\end{tabular}


Kim K, et al. - Elastic band exercises with breathing techniques

Table 3. The comparison of means for variables for the two groups (unit: L)

\begin{tabular}{|c|c|c|c|c|c|c|}
\hline \multirow{2}{*}{ Pulmonary function } & \multicolumn{3}{|c|}{ EBE+MEP group } & \multicolumn{3}{|c|}{ EBE group } \\
\hline & Prevalue & Postvalue & Difference value & Prevalue & Postvalue & Difference value \\
\hline FVC & $1.99 \pm 0.40$ & $2.23 \pm 0.42^{*}$ & $0.24 \pm 0.17^{\dagger}$ & $2.04 \pm 0.52$ & $2.09 \pm 0.52$ & $0.05 \pm 0.20$ \\
\hline $\mathrm{FEV}_{1}$ & $1.77 \pm 0.36$ & $1.89 \pm 0.32^{*}$ & $0.12 \pm 0.04^{\dagger}$ & $1.71 \pm 0.47$ & $1.67 \pm 0.47$ & $-0.03 \pm 0.09$ \\
\hline $\mathrm{FEV}_{1} / \mathrm{FVC}$ & $87.78 \pm 5.20$ & $90.47 \pm 2.74^{*}$ & $2.69 \pm 6.16$ & $85.52 \pm 5.51$ & $85.70 \pm 10.24$ & $0.17 \pm 9.18$ \\
\hline PEF & $3.99 \pm 1.18$ & $4.04 \pm 1.27$ & $0.05 \pm 0.43$ & $3.30 \pm 0.95$ & $3.14 \pm 0.90$ & $-0.16 \pm 0.34$ \\
\hline
\end{tabular}

Values are presented as mean \pm standard deviation.

EBE+MEP group, elastic band exercise+maximal expiratory technique group; EBE group, elastic band exerciser group; FVC, forced vital capacity; FEV ${ }_{1}$, forced expiratory volume at $1 \mathrm{sec}$; PEF, peak expiratory flow.

Difference: difference between pretest value and posttest value.

*Significantly different between pre and post $(P<0.05)$. ${ }^{\dagger}$ Significantly different between the group $(P<0.05)$.

Cosmed, Rome, Italy). Subjects gazed ahead while seated in a chair with a backrest and measurement began one minute after taking a seat. To measure the pulmonary function, subjects were asked to breathe normally 3 times, then inhale as deeply as possible without considering the time taken, and then exhale as quickly as possible until they could no longer breathe. They were then asked to inhale again with maximum effort as quickly as possible and with all possible strength. Once measurement was complete, the stop button was pushed by the experimenter to notify participants who then took a rest. The items measured were the forced vital capacity (FVC), forced expired volume in $1 \mathrm{sec}\left(\mathrm{FEV}_{1}\right), \mathrm{FEV}_{1}$ as a percentage of $\mathrm{FVC}\left(\mathrm{FEV}_{1} / \mathrm{FVC}\right)$, and peak expiratory flow (PEF). All measurements were conducted three times and the maximum value was used. The unit of air volume measured was $\mathrm{L}$.

A previous study reported that a strength of $40 \%$ to $60 \%$ of 1RM should be applied to participants who did not perform regular exercise or had not trained before (Page, 2000). Thus, in this study, a strength of $50 \%$ of $1 \mathrm{RM}$ was applied for the group using the elastic band based on the exercise ability of female seniors.

\section{Statistical analysis}

Statistical analysis was performed using IBM SPSS Statistics ver. 22.0 (IBM Co., Armonk, NY, USA). The Shapiro-Wilk test was employed to check the normal distribution of the data, while a paired $t$-test was conducted to compare respiratory function within the groups before and after the intervention and the independent $t$-test was performed to compare changes in the variables the groups. The level of significance was set at $P=0.05$.

\section{RESULTS}

\section{Comparison of FVC and FEV}

Paired sample $t$-tests revealed significant differences in FVC and $\mathrm{FEV}_{1}$ before and after the experiment $(P<0.05)$ for the group using the breathing technique to accompany the resistance exercise, whereas no significant difference was observed for the group using only the elastic band $(P>0.05)$. An independent sample $t$-test compared the results of the two groups and revealed a significant difference $(P<0.05)$ (Table 3$)$.

\section{Comparison of $\mathrm{FEV}_{1} / \mathrm{FVC}$}

A paired sample $t$-test revealed a significant difference in $\mathrm{FEV}_{1} /$ FVC for the elastic band and breathing group before and after the experiment $(P<0.05)$, whereas results for the group using only the elastic band did not differ significantly before and after the experiment $(P>0.05)$. In addition, an independent sample $t$-test comparing the results of the two groups revealed no significant difference $(P>0.05)$ (Table 3$)$.

\section{Comparison of PEF}

A paired sample $t$-test comparing PEF levels within each group showed that neither exhibited a significant difference before and after the experiment $(P>0.05)$. In addition, an independent sample $t$-test comparing the results of the two groups revealed no significant difference $(P>0.05)$ (Table 3).

\section{DISCUSSION}

Degradation in pulmonary function, which begins at the age of 30 , occurs as a result of reduced flexibility of the thoracic cage and weakening respiration muscles, as well as changes in the lungs, increases in air flow resistance and reduced FVC, $\mathrm{FEV}_{1}, \mathrm{FEV}_{1} /$ FVC, and PEF. These changes result in increased physical fatigue and difficulties breathing, which degrades the quality of a healthy and active life (Dyer, 2012; Lalley, 2013; Miller et al., 2005; Stanojevic et al., 2008). Accordingly, there is a need for regular and 
various, as well as efficient, exercise to solve this problem (Dishman et al., 2006). Therefore, this study investigated the effects of resistance exercise using bands accompanied by a breathing technique on pulmonary function in female seniors.

The pulmonary function test results show a significant increase in FVC and $\mathrm{FEV}_{1}$ before and after the experiment in the group with the added breathing technique, whereas the elastic band-only exercise group had no significant increases. In addition, there was a significant difference between the two groups. FVC and $\mathrm{FEV}_{1}$ are reduced in aging as a result of a reduction in lung capacity, pressure in the chest wall, respiratory muscle mass, and narrow airways (Lalley, 2013). During the intervention of elastic band exercise with accompanying breathing technique, this study revealed that $\mathrm{FVC}$ and $\mathrm{FEV}_{1}$ increased by associating peak expiratory breath with a functional method to activate the abdominal muscles as much as possible (Neumann, 2010). The elastic band exercise with the breathing technique simultaneously contracted the respiratory muscles that are used during peak expiration, namely the external and internal obliques and the rectus abdominis (Knox and Evans, 2002). The thickness and activation of the abdominal muscles increased during the resistance exercise using elastic bands.

The elastic band with breathing technique group showed a significant increase in $\mathrm{FEV}_{1} / \mathrm{FVC}$, whereas the group using just the band showed no significant difference. In addition, a significant difference was not shown between groups. For those over 65 years of age, $\mathrm{FEV}_{1} / \mathrm{FVC}$ decreases through expansion of the alveolar duct and bronchi, as well as through reductions in lung elasticity and muscle strength, with the latter being caused by a respiratory muscle mass weakened by aging (Lalley, 2013). The results of this study support the conclusion that peak expiration breathing with an elastic band exercise program strengthens pulmonary function and skeletal muscles activate abdominal muscles via the intervention used in this study. As reported by Enright et al. (1994), such muscles and pulmonary function in the elderly are correlated.

Neither group showed a significant difference in PEF before and after the experiment. And no significant difference was found between the two groups. This result occurred because PEF is dependent on age (Kim and Sapienza, 2005); specifically, reduced elasticity in the airway and increased secretion due to aging restrict the air flow and reduce PEF (Dyer, 2012; Lalley, 2013). A study by Ishida and Watanabe (2015) recommended selective strengthening exercises that focus on the external oblique to improve PEF, but the intervention used in the present study omitted their recommendation. Thus, it is implied that additional exercis- es to increase the flexibility of the chest walls and to develop the external oblique are needed to increase PEF (Sapienza et al., 2011).

In summary, this study showed that an elastic band exercise with breathing technique effectively increased the FVC, FEV 1 and $\mathrm{FEV}_{1} / \mathrm{FVC}$ of female seniors. This implies that elastic band resistance and breathing exercises can contribute to the composition of clinical exercise programs that are more effective for the elderly. It should be noted that this study was limited in that a post boc investigation was not conducted through follow-up after the experiment; therefore, continued use of the intervention method was not verified.

The results of this study revealed that an elastic band exercise accompanied by a specific breathing technique had a positive effect that could prove highly effective at improving pulmonary function. The intervention method used in this study can therefore be used as an elastic band exercise regime for improvements in pulmonary function during the planning of clinical and family programs.

\section{CONFLICT OF INTEREST}

No potential conflict of interest relevant to this article was reported.

\section{ACKNOWLEDGMENTS}

This research was supported by a Daegu University Research Grant in 2016.

\section{REFERENCES}

Andersen LL, Andersen CH, Mortensen OS, Poulsen OM, Bjørnlund IB, Zebis MK. Muscle activation and perceived loading during rehabilitation exercises: comparison of dumbbells and elastic resistance. Phys Ther 2010;90:538-549.

Bradley $\mathrm{H}$, Esformes J. Breathing pattern disorders and functional movement. Int J Sports Phys Ther 2014;9:28-39.

Colado JC, Triplett NT. Effects of a short-term resistance program using elastic bands versus weight machines for sedentary middle-aged women. J Strength Cond Res 2008;22:1441-1448.

Dishman RK, Berthoud HR, Booth FW, Cotman CW, Edgerton VR, Fleshner MR, Gandevia SC, Gomez-Pinilla F, Greenwood BN, Hillman CH, Kramer AF, Levin BE, Moran TH, Russo-Neustadt AA, Salamone JD, Van Hoomissen JD, Wade CE, York DA, Zigmond MJ. Neurobiology of exercise. Obesity (Silver Spring) 2006;14:345-356. 
Dyer C. The interaction of ageing and lung disease. Chron Respir Dis 2012;9:63-67.

Enright PL, Kronmal RA, Manolio TA, Schenker MB, Hyatt RE. Respiratory muscle strength in the elderly. Correlates and reference values. Cardiovascular Health Study Research Group. Am J Respir Crit Care Med 1994;149(2 Pt 1):430-438.

Hodges PW, Gandevia SC. Changes in intra-abdominal pressure during postural and respiratory activation of the human diaphragm. J Appl Physiol (1985) 2000;89:967-976.

Hodges PW, Richardson CA. Transversus abdominis and the superficial abdominal muscles are controlled independently in a postural task. Neurosci Lett 1999;265:91-94.

Hostler D, Schwirian CI, Campos G, Toma K, Crill MT, Hagerman GR, Hagerman FC, Staron RS. Skeletal muscle adaptations in elastic resistance-trained young men and women. Eur J Appl Physiol 2001;86:112118.

Ishida $\mathrm{H}$, Hirose $\mathrm{R}$, Watanabe $\mathrm{S}$. Comparison of changes in the contraction of the lateral abdominal muscles between the abdominal drawing-in maneuver and breathe held at the maximum expiratory level. Man Ther 2012;17:427-431.

Ishida $\mathrm{H}$, Watanabe S. Maximum expiration activates the abdominal muscles during side bridge exercise. J Back Musculoskelet Rehabil 2015;28:81-84.

Jakobsen MD, Sundstrup E, Andersen CH, Bandholm T, Thorborg K, Zebis MK, Andersen LL. Muscle activity during knee-extension strengthening exercise performed with elastic tubing and isotonic resistance. Int J Sports Phys Ther 2012;7:606-616.

Janssens JP, Pache JC, Nicod LP. Physiological changes in respiratory function associated with ageing. Eur Respir J 1999;13:197-205.

Khedr EM, El Shinawy O, Khedr T, Abdel aziz ali Y, Awad EM. Assessment of corticodiaphragmatic pathway and pulmonary function in acute ischemic stroke patients. Eur J Neurol 2000;7:509-516.

Kim J, Sapienza CM. Implications of expiratory muscle strength training for rehabilitation of the elderly: tutorial. J Rehabil Res Dev 2005;42: 211-224.

Knox V, Evans AL. Evaluation of the functional effects of a course of Bo- bath therapy in children with cerebral palsy: a preliminary study. Dev Med Child Neurol 2002;44:447-460.

Koppers RJ, Vos PJ, Boot CR, Folgering HT. Exercise performance improves in patients with COPD due to respiratory muscle endurance training. Chest 2006;129:886-892.

Lalley PM. The aging respiratory system-pulmonary structure, function and neural control. Respir Physiol Neurobiol 2013;187:199-210.

Miller MR, Hankinson J, Brusasco V, Burgos F, Casaburi R, Coates A, Crapo R, Enright P, van der Grinten CP, Gustafsson P, Jensen R, Johnson DC, MacIntyre N, McKay R, Navajas D, Pedersen OF, Pellegrino R, Viegi G, Wanger J; ATS/ERS Task Force. Standardisation of spirometry. Eur Respir J 2005;26:319-338.

Moodie L, Reeve J, Elkins M. Inspiratory muscle training increases inspiratory muscle strength in patients weaning from mechanical ventilation: a systematic review. J Physiother 2011;57:213-221.

Neumann DA. Kinesiology of the hip: a focus on muscular actions. J Orthop Sports Phys Ther 2010;40:82-94.

Nyberg A, Lindström B, Rickenlund A, Wadell K. Low-load/high-repetition elastic band resistance training in patients with COPD: a randomized, controlled, multicenter trial. Clin Respir J 2015;9:278-288.

Obayashi H, Urabe Y, Yamanaka Y, Okuma R. Effects of respiratory-muscle exercise on spinal curvature. J Sport Rehabil 2012;21:63-68.

Page P. Clinical force production of thera-band elastic bands. J Orthop Sports Phys Ther 2000;30:A47-48.

Perri MA, Halford E. Pain and faulty breathing: a pilot study. J Bodyw Mov Ther 2004;8:297-306.

Sapienza C, Troche M, Pitts T, Davenport P. Respiratory strength training: concept and intervention outcomes. Semin Speech Lang 2011;32:21-30.

Stanojevic S, Wade A, Stocks J, Hankinson J, Coates AL, Pan H, Rosenthal M, Corey M, Lebecque P, Cole TJ. Reference ranges for spirometry across all ages: a new approach. Am J Respir Crit Care Med 2008;177: 253-260.

Sutbeyaz ST, Koseoglu F, Inan L, Coskun O. Respiratory muscle training improves cardiopulmonary function and exercise tolerance in subjects with subacute stroke: a randomized controlled trial. Clin Rehabil 2010; 24:240-250 